\title{
XÂY DỰNG Hệ ĐO GAMMA ĐƠN KÊNH ÚNG DỤNG KỸ THUẬT TRUYỀN PHÁT KHÔNG DÂY
}

\author{
Lại Viết Hải ${ }^{(1)}$, Vương Đức Phụng ${ }^{(1)}$ \\ (1) Trung tâm Ứng dụng kỹ thuật hạt nhân trong công nghiệp \\ Ngày nhận bài 05/01/2020; Ngày gưi phản biện 08/01/2020; Chấp nhận đăng 28/01/2020 \\ Liên hệemail: hailv@canti.vn
}

https://doi.org/10.37550/tdmu.VJS/2020.01.016

\section{Tóm tắt}

Phương pháp gamma truyền qua dựa trên nguyên lý suy giảm cuoòng độ chùm tia gamma khi truyền qua vật chất được biết đến là một trong nhũng kỹ thuật hũu ích cho phép kiểm tra trực tiếp các tháp và đường ống công nghiệp. Trong đó, hầu hết việc truyền tín hiệu tù đầu dò đến máy đo sủ dụng cáp dẫn đến nhiều khó khăn trong việc lắp đặt và vận hành hệ đo tại hiện truờng. Nhằm tăng tính linh hoạt, hệ đo gamma đơn kênh ưng dụng công nghệ truyền phát không dây trong điều khiển và thu nhận tín hiệu đã được đề xuất trong bài báo này. Hệ đo gồm các khối điện tủ nhu khối cao thế, khối khuếch đại, khối cắt ngương, khối vi điều khiển và khối truyền phát không dây. Thí nghiệm khảo sát phổ gamma của nguồn ${ }^{60}$ Co và ${ }^{137}$ Cs sau đó được thực hiện với khoảng cách giữa hệ đo và điểm đo khoảng $230 \mathrm{~m}$. Kết quả cho thấy bề rộng ở một nưa giá trị cục đại ứng với các đỉnh năng lương lần lượ là $F W H M^{1173 \mathrm{KeV}}=9,4 \%$ và $\mathrm{FWHM}^{1332 \mathrm{KeV}}=7.6 \%$ đối với phổ gamma ${ }^{60} \mathrm{Co}$ và $F W H M^{663 \mathrm{KeV}}=15,4 \%$ đối với phổ gamma ${ }^{137} \mathrm{Cs}$. Kết quả khảo sát sụ ổn định của hệ đo trong 10 giờ cho thấy độ trôi đỉnh năng lựng của nguồn ${ }^{60}$ Co là khoảng 2,3\%.

Tù khóa: công nghiệp, hệ đo gamma, phổ gamma, truyền phát không dây

\section{Abtract}

\section{CONSTRUCTION OF A SINGLE-CHANNEL GAMMA ANALYZER APPLYING THE WIRELESS TRANSFER TECHNIQUE}

The gamma transmission method based on the principle of reducing the intensity of the gamma rays when passing through a material is well-known as one of the useful techniques for industrial system inspections. In particular, most of the signal transmission from a detector to a spectrometer using cables leads to many difficulties in installing and operating the measuring system in the field conditions. For enhanced flexibility, a singlechannel gamma analyzer applying the wireless transfer technique in controlling and receiving signals was proposed in this paper. The measuring system consists of electronic units such as high-voltage, amplifier, discriminator, microcontroller, and wireless transfer. The experiment of surveying the gamma spectrum of source ${ }^{60}$ Co and ${ }^{137} \mathrm{Cs}$ was then carried out with the distance between the measuring system and the measuring point about 
$200 \mathrm{~m}$. The results show that the full width at half maximum corresponding to the energy peaks is respectively $F W H M^{1173 \mathrm{KeV}}=9.4 \%$ and $F W H M^{1332 \mathrm{KeV}}=7.6 \%$ for ${ }^{137}$ Co gamma spectrum and $F W H M^{663 \mathrm{KeV}}=15.4 \%$ for ${ }^{137} \mathrm{Cs}$ gamma spectrum. Results of the stability survey of the measuring system for 10 hours show that the peak energy drift of the ${ }^{60} \mathrm{Co}$ source is about $2.3 \%$.

\section{1. Đặt vấn đề}

Tia gamma là một dạng của bức xạ điện từ, được phát ra khi hạt nhân nguyên tử chuyển từ trạng thái kích thích về trạng thái cơ bản trong các phản ứng hạt nhân, được phát hiện vào năm 1900 bởi nhà hóa học và vật lý học người Pháp Paul Villard thông qua nghiên cứu về sự phát xạ của radium (Gerward \& Rassat, 2000). Đến nay, ứng dụng kỹ thuật gamma truyền qua được xem là một trong những phương pháp kiểm tra không phá hủy lý tưởng cho phép xác định mật độ vật chất bên trong tháp và đường ống công nghiệp. Trong đó, khi một chùm tia từ nguồn (như $\left.{ }^{137} \mathrm{Cs},{ }^{60} \mathrm{Co}\right)$ đi qua hệ thống và được ghi nhận bởi hệ đo bức xạ, mức độ suy giảm cường độ chùm tia phụ thuộc vào năng lượng của chùm tia, mật độ và bề dày vật liệu theo định luật Beer - Lambert (Trịnh \& Hoàng, 2019). Hệ đo gamma này cấu tạo bởi khối đầu dò nối với khối xử lý điện tử/xử lý tín hiệu gồm tiền khuếch đại, khuếch đại và hầu hết sử dụng bộ phân tích đơn kênh. Kiểu đầu dò sử dụng tinh thể nhấp nháy $\mathrm{NaI}(\mathrm{Tl})$ thường được chọn để ghi đo bức xạ gamma bởi nhiều ưu điểm về cường độ nháy sáng và giá thành. Khi bức xạ đi qua môi trường vật liệu nhấp nháy và ion hóa các phân tử, các photon ánh sáng được sinh ra. Các photon sau đó đi vào ống nhân quang điện và tạo ra một các xung điện với biên độ mỗi xung ứng với năng lượng của bức xạ (Trần, Châu \& Nguyễn, 2005). Bộ phân tích đơn kênh (Single - channel analyzer hay SCA) từ lâu được biết đến là bộ chuyển đổi tương tự sang số cơ bản cho phép xác định biên độ xung ứng dụng rộng rãi trong ghi đo hạt nhân. SCA có hai mức điện áp ngưỡng có thể điều chỉnh và tạo ra xung đầu ra khi biên độ của xung tín hiệu đầu vào nằm giữa hai mức này (Milam, 1973). Vùng giữa hai mức điện áp được gọi là cửa sổ. Tất cả các xung bên ngoài cửa sổ SCA đều bị bỏ qua, do đó cửa sổ càng nhỏ độ phân giải của hệ đo càng tốt.

Hiện nay, hầu hết hệ đo gamma ứng dụng trong công nghiệp sử dụng cáp để truyền tín hiệu từ đầu dò đến máy đo dẫn đến nhiều khó khăn trong việc lắp đặt cũng như vận hành hệ đo tại hiện trường. Nhằm cải tiến tính cơ động cho hệ đo, báo cáo này trình bày một số kết quả nghiên cứu xây dựng hệ đo gamma đơn kênh ứng dụng công nghệ truyền phát không dây Zigbee trong điều khiển và thu nhận tín hiệu.

\section{Vật liệu và phương pháp}

\subsection{Thiết kế và chế tạo hệ đo}

Hệ đo gamma đơn kênh sử dụng kỹ thuật truyền phát không dây được xây dựng từ các khối cơ bản như hình 1 . Khi các bức xạ gamma tương tác với Khối đầu dò $\mathrm{NaI}(\mathrm{Tl})$ 
(1) sẽ tạo ra các xung điện với biên độ nhỏ. Xung điện sau đó được đưa vào Khối khuếch đại (3) để khuếch đại biên độ và hình thành dạng xung Gauss. Sau khi qua Khối cắt ngưỡng (4), các xung dạng Gauss được chuyển thành các xung vuông theo chuẩn TTL. Khối vi điều khiển (5) có chức năng đếm xung theo thời gian, điều khiển và đo lường cao thế (2), điều khiển và đo lường giá trị điện áp ngưỡng và giao tiếp với module RF (6) bằng giao diện UART để nhận các lệnh điều khiển và truyền giá trị đo về máy tính (7). Máy tính (7) có chức năng điều khiển, thu nhận và lưu trữ các giá trị đo thông qua phần mềm điều khiển.

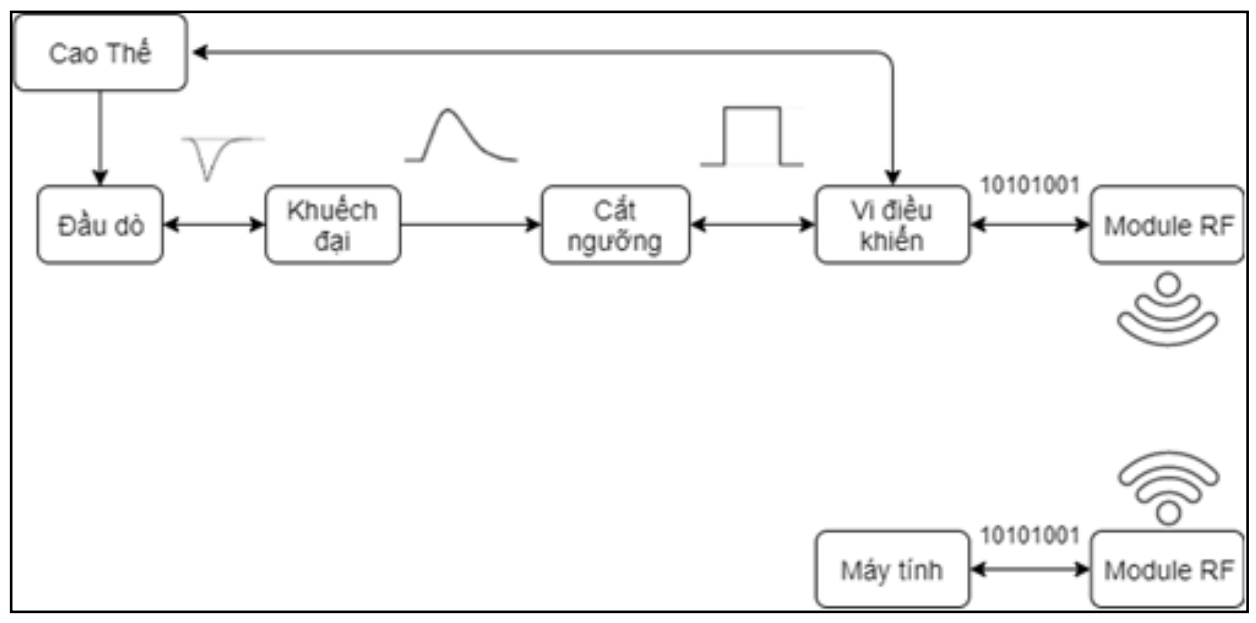

Hinh 1. So đồ khối hệ đo gamma đơn kênh không dây.

Đầu dò NaI(Tl): Đối với các ứng dụng bức xạ gamma trong công nghiệp, loại đầu dò nhấp nháy kết hợp ống nhân quang điện thường được sử dụng bởi nhiều ưu điểm về độ nhạy, tính linh hoạt trong lắp đặt và giá thành. Hệ đo này sử dụng đầu dò $\mathrm{NaI}(\mathrm{Tl})$ của hãng Ludlum Measurements (Model M44-10) (hình 2) với kích thước khối tinh thể 2 inch x 2 inch, điện áp hoạt động từ $500 \mathrm{~V}-1200 \mathrm{~V}$ và dải năng lượng đo được từ $30 \mathrm{KeV}-3 \mathrm{MeV}$.

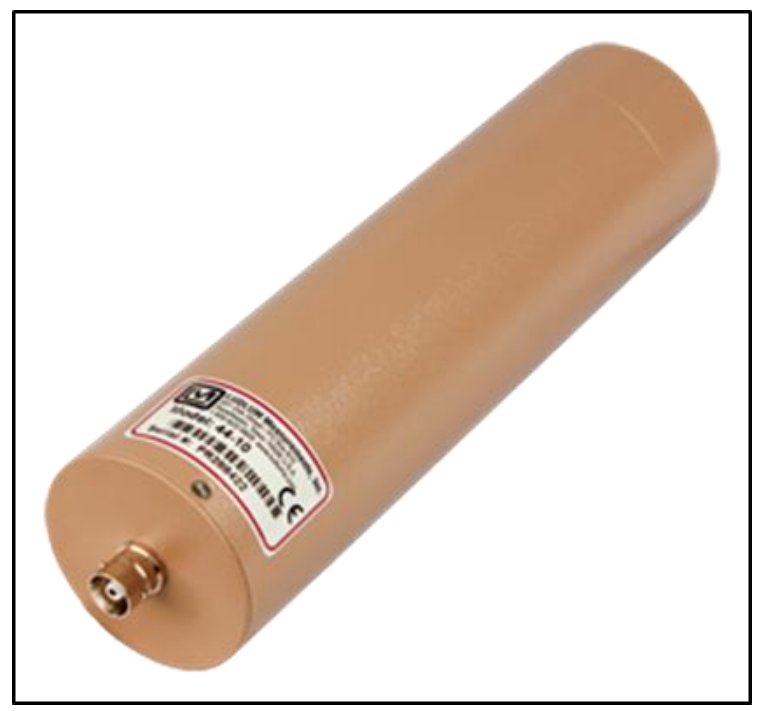

Hình 2. Đầu dò NaI(Tl) của hãng Ludlum Measurements (Model 44-10). 
Khối cao thế: Các đầu dò sử dụng ống nhân quang điện kết hợp tinh thể nhấp nháy như $\mathrm{NaI}(\mathrm{Tl})$ thường có điện áp hoạt động lớn từ vài trăm đến vài nghìn Volt, do đó chức năng của khối cao thế là cung cấp đủ điện áp để đầu dò hoạt động ổn định. Khối cao thế được xây dựng bao gồm: IC tạo xung, biến thế, mạch nhân điện CockcroftWalton và mạch phản hồi (hình 3 ).
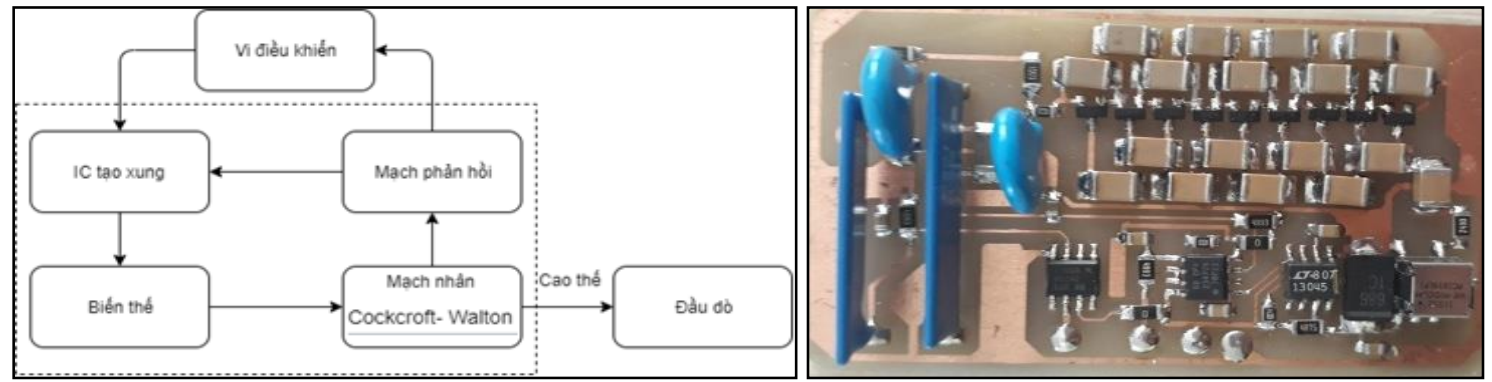

Hinh 3. So đồ hoạt động của khối cao thế và khối cao thế được chế tạo hoàn chinh.

IC tạo xung có chức năng tạo ra xung có tần số cố định để điều khiển biến thế. Biến thế sử dụng biến thế tăng áp, dòng điện qua biến thế có điện áp được nhân lên theo tỉ lệ giữa số vòng thứ cấp và số vòng sơ cấp. Dòng điện sau đó được đưa vào mạch nhân điện Crockcroft-Walton để chỉnh lưu và nhân lên nhiều lần hơn. Mạch phản hồi gồm mạch chia áp sử dụng điện trở và mạch khuếch đại đệm sử dụng op-amp. Mạch phản hồi có chức năng chia điện áp cao thành các mức điện áp nhỏ đủ để đưa vào $\mathrm{ADC}$ của vi điều khiển và chân "feedback" của IC tạo xung. Khối cao thế sau khi chế tạo có thể cấp cao thế từ $50 \mathrm{~V}$ dến $2500 \mathrm{~V}$ (hình 3 ).

Khối khuếch đại: Khối khuếch đại có chức năng khuếch đại tín hiệu từ đầu dò và tạo dạng xung phù hợp để đưa vào Khối cắt ngưỡng. Khối khuếch đại gồm các mạch tiền khuếch đại, mạch vi phân và mạch tích phân (hình 4).
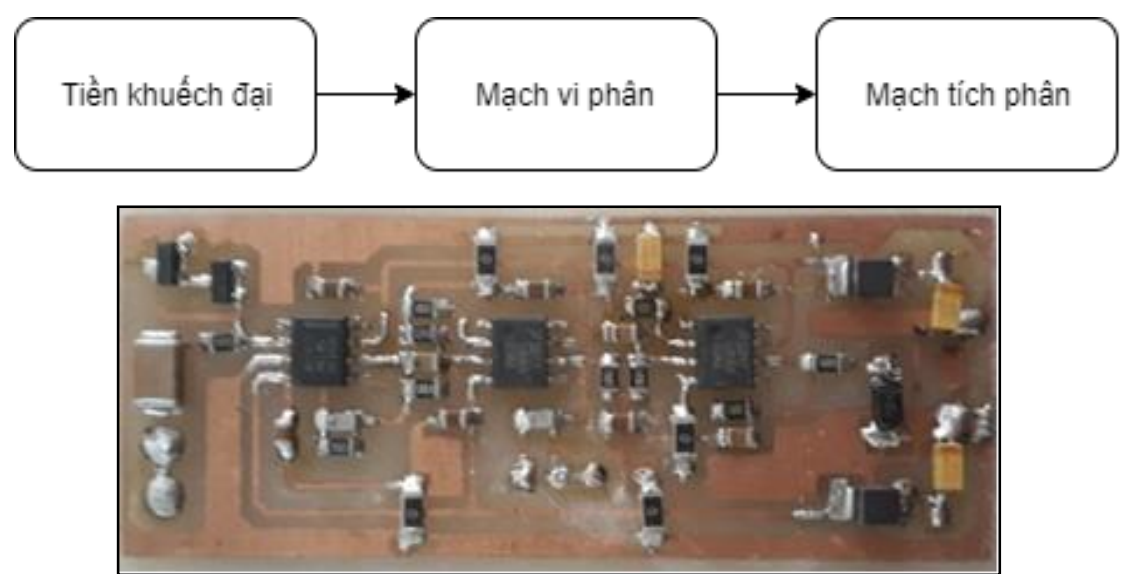

Hình 4. So đồ của khối khuếch đại và khối khuếch đại được chế tạo hoàn chỉnh.

Khối cắt ngưỡng: Chức năng của khối cắt ngưỡng là phân biệt biên độ xung của tín hiệu vào. Hình 5 mô tả khối cắt ngưỡng được chế tạo hoàn chỉnh. Hình 6 tương ứng minh họa tốc độ đáp ứng của Khối cắt ngưỡng. 


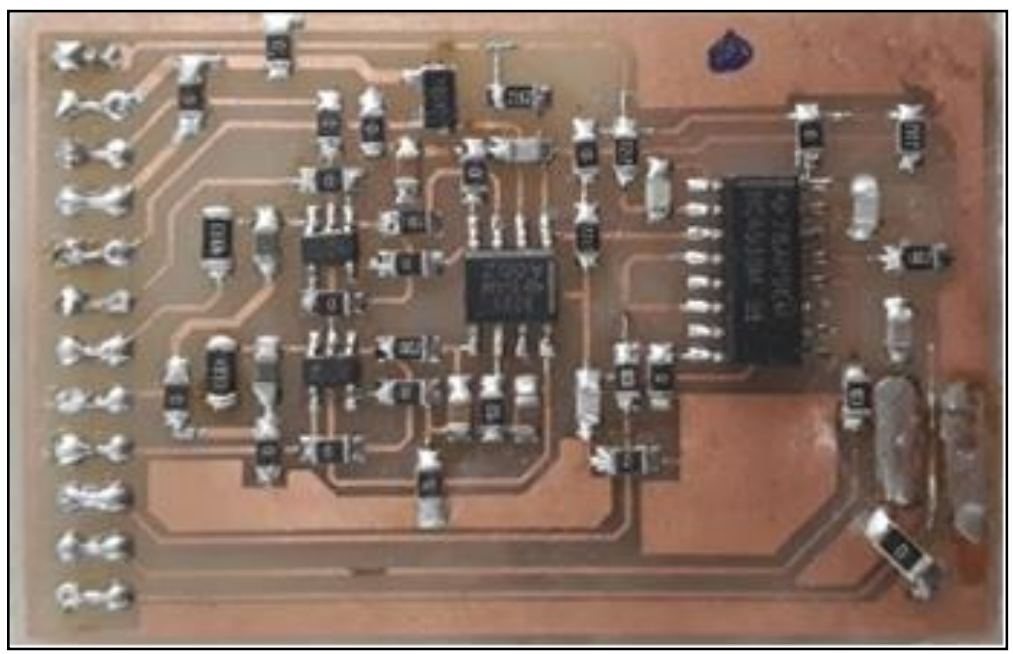

Hinh 5. Khối cắt ngương được chế tạo hoàn chỉnh.

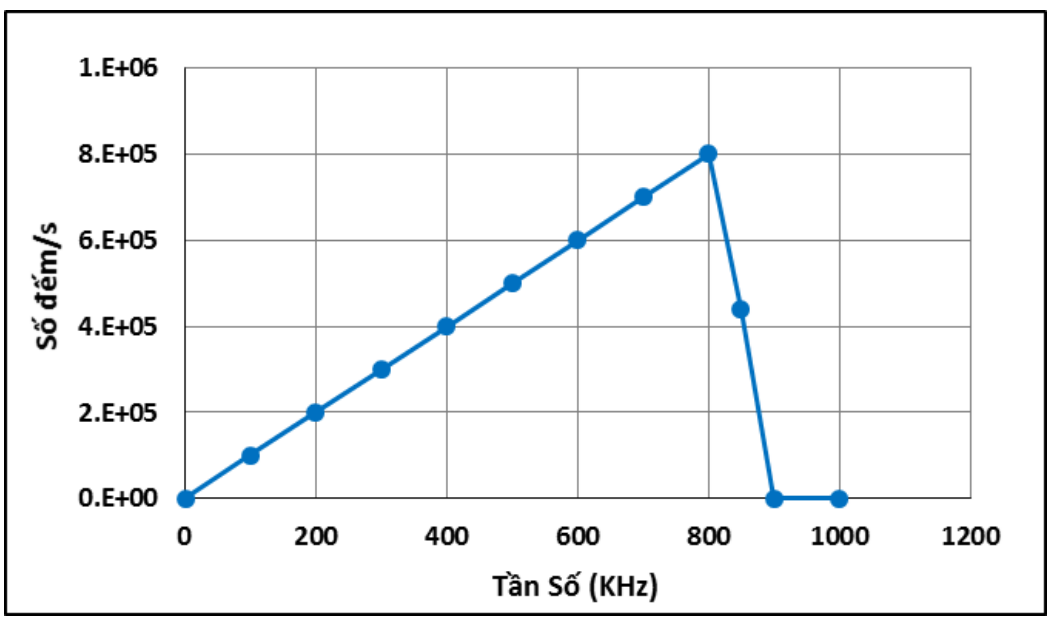

Hình 6. Tốc độ đáp úng của khối cắt ngương.

Khối vi điều khiển: Khối vi điều khiển sử dụng Module Arduino Mega 2560 Pro làm khối điều khiển chính với chức năng giao tiếp với máy tính thông qua Module RF, điều khiển khối cao thế và khối cắt ngưỡng và đếm xung theo thời gian.

Module RF: Module RF sử dụng mạch thu phát RF Zigbee UART CC2530+PA V2, IC CC2530 kết hợp với tầng khuếch đại công suất PA CC2591 cho khoảng cách truyền có thể đạt tới $1000 \mathrm{~m}$ trong điều kiện lý tưởng. Module được thiết kế theo chuẩn công nghiệp với ưu điểm ổn định và dễ dàng kết nối với vi điều khiển hoặc máy tính thông qua cáp chuyển USB-UART.

\subsection{Phần mềm điều khiển}

Phần mềm điều khiển hệ đo trên máy tính được lập trình bằng ngôn ngữ $\mathrm{C}++$ với các chức năng như tự động khảo sát phổ vi phân, tự động khảo sát cao thế của đầu dò, thiết lập các thông số đặc trưng của hệ đo gồm cao thế, ngưỡng trên, ngưỡng dưới, thời gian đo, cũng như cho phép lưu trữ và đồ thị hóa dữ liệu. Giao diện phần mềm được minh họa như hình 7. 


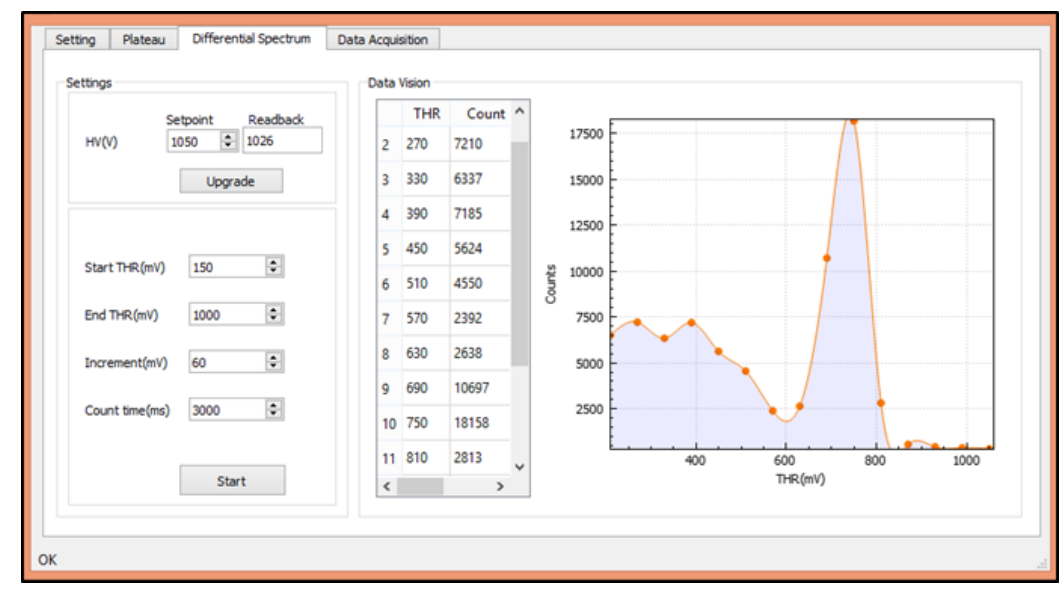

Hinh 7. Giao diện chuơng trình điều khiển hệ đo trên máy tính.

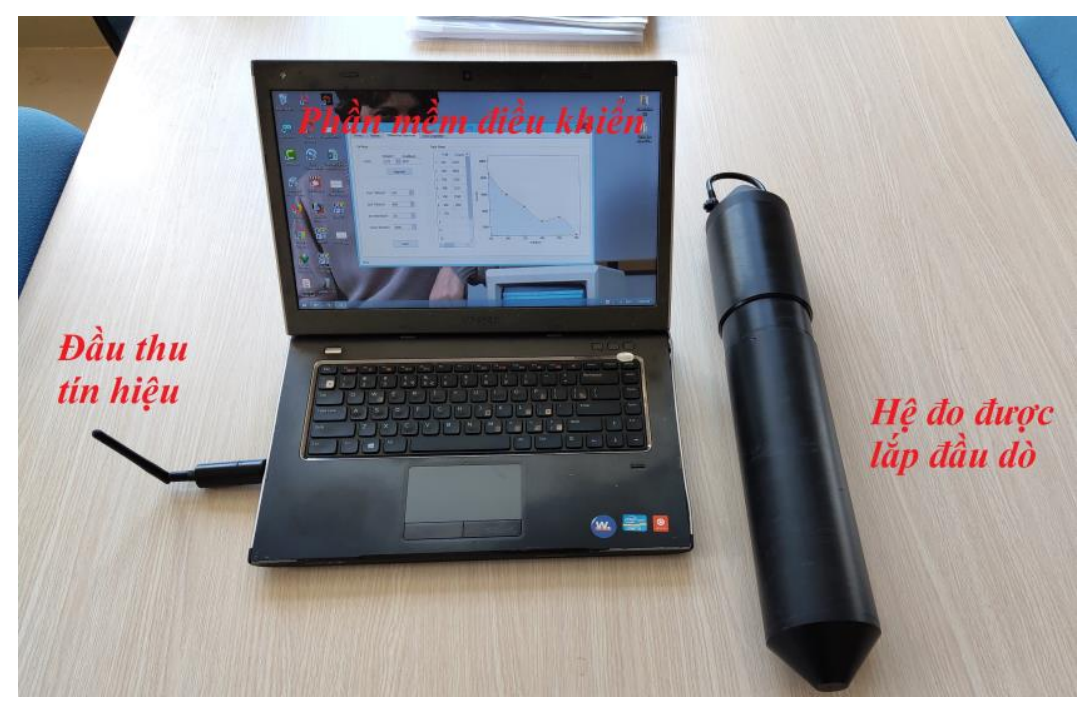

Hình 8. Hệ đo hoàn thiện.

\section{Kết quả nghiên cứu}

Hệ đo sau khi xây dựng được khảo sát độ phân giải năng lượng và độ ổn định sử dụng nguồn chuẩn ${ }^{60} \mathrm{Co}-0,1 \mu \mathrm{Ci}$ và ${ }^{137} \mathrm{Cs}-10,89 \mu \mathrm{Ci}$ tại Trung tâm Ứng dụng kỹ thuật hạt nhân trong công nghiệp (thuộc Viện Năng lượng nguyên tử Việt Nam, tại thành phố Đà Lạt, tỉnh Lâm Đồng). Thông số thí nghiệm gồm được trình bày trong bảng 1.

Bảng 1. Thông số thí nghiệm khảo sát hệ đo.

\begin{tabular}{ll}
\hline Thông số & Giá trị \\
\hline Cao thế áp vào đầu dò & $1200 \mathrm{~V}$ \\
Độ rộng cửa sổ & $50 \mathrm{mV}$ \\
Thời gian mỗi lần dịch chuyển cửa sổ & $3 \mathrm{~s}$ \\
Khoảng cách truyền phát & $230 \mathrm{~m}$ \\
\hline
\end{tabular}


Kết quả khảo sát độ phân giải năng lượng của hệ đo được trình bày trên hình 9 và hình 10. Trong đó, độ phân giải năng lượng của nguồn ${ }^{60} \mathrm{Co}$ là $9,4 \%$ và $7,6 \%$ tương ứng với hai đỉnh năng lượng là $1173 \mathrm{KeV}$ và $1332 \mathrm{KeV}$. Độ phân giải năng lượng của nguồn ${ }^{137} \mathrm{Cs}$ là $15,4 \%$ tương ứng với đỉnh năng lượng là $662 \mathrm{KeV}$.

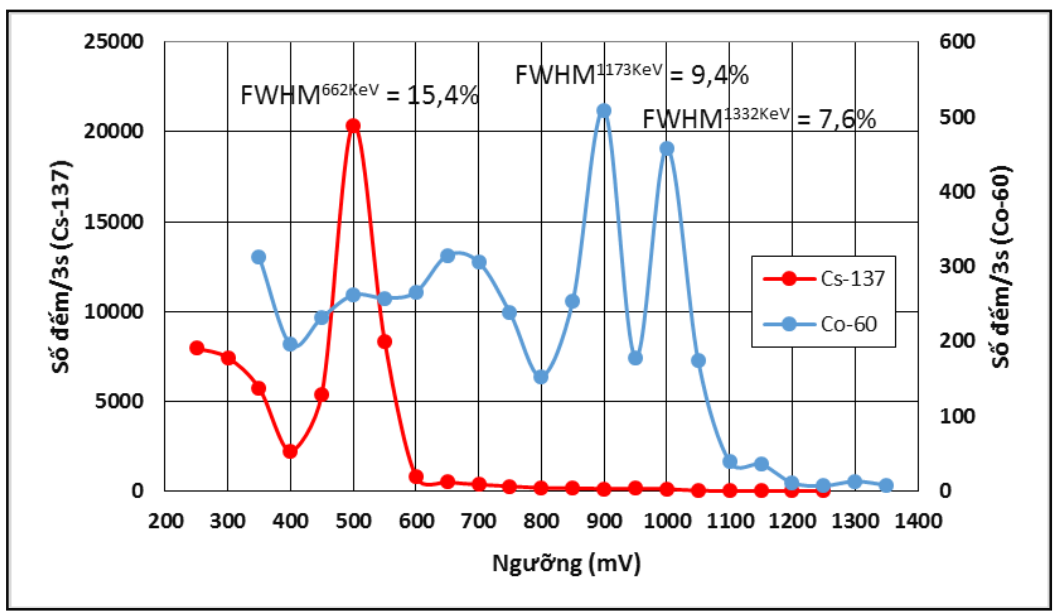

Hình 9. Kết quả đo phổ gamma của nguồn ${ }^{60}$ Co và ${ }^{137}$ Cs.

Độ ổn định của hệ đo được khảo sát trên phổ năng lượng của nguồn ${ }^{60} \mathrm{Co}$ trong khoảng thời gian 10 giờ. Kết quả được minh họa trong hình 10 cho thấy độ lệch đỉnh phổ là là $2,3 \%$.

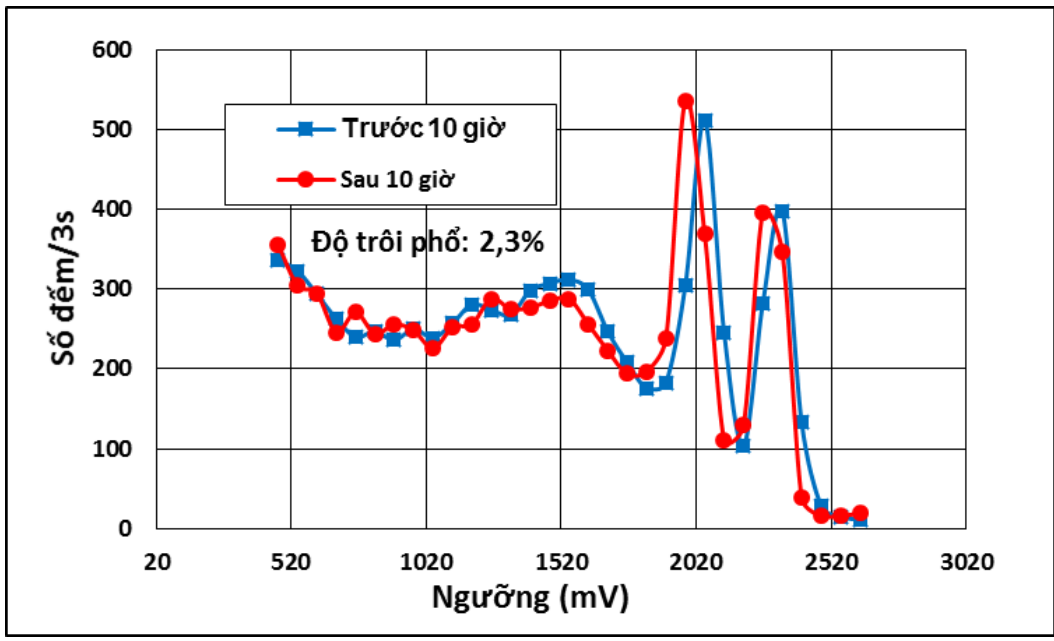

Hình 10. Độ lệch của phổ năng lượng nguồn $\mathrm{Co}^{60}$ trước và sau 8 giờ.

Ngoài ra, hệ đo gamma đơn kênh không dây được sử dụng để khảo sát trên tháp mô hình nhằm xác định khả năng ứng dụng trong kỹ thuật soi tháp. Tháp mô hình mô phỏng theo tháp chưng cất trong nhà máy lọc hóa dầu với chiều cao gần $6 \mathrm{~m}$ và chiều rộng khoảng $0,57 \mathrm{~m}$, bên trong có chứa các khay nước và sỏi xây dựng. Nguồn phóng xạ dùng để khảo sát là nguồn ${ }^{137} \mathrm{Cs} 1 \mathrm{mCi}$, các thông số khác như thí nghiệm ban đầu. Các kết quả được so sánh với hệ đo M2200 của Ludlum trình bày trong hình 12 . 


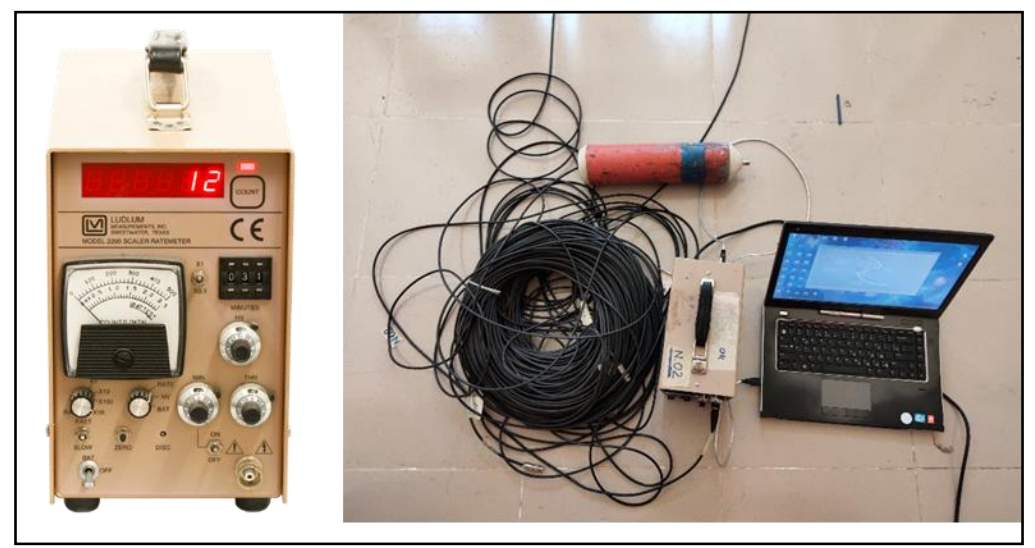

Hình 11. Hệ đo M2200 của hãng Ludlum dùng trong soi tháp tại CANTI.

Bảng 2. So sánh giũa hệ đo gamma đơn kênh không dây và hệ đo M2200 của Ludlum.

\begin{tabular}{|c|c|c|}
\hline Thông số & Hệ đo gamma đơn kênh không dây & Hệ đo M2200 của Ludlum \\
\hline Loại dây cáp sử dụng & Không dây & Cáp đồng trục \\
\hline Khoảng cách truyền phát & $\begin{array}{c}230 \mathrm{~m} \text { (trong trường hợp lý tưởng có } \\
\text { thể lên đến } 1000 \mathrm{~m})\end{array}$ & Tối đa $150 \mathrm{~m}$ \\
\hline Thời gian hoạt động & 10 giờ (dùng pin) & 1 giờ (dùng pin) \\
\hline Cơ chế điều khiển & Điều khiển từ xa qua phần mềm & $\begin{array}{c}\text { Điều khiển cơ học thông qua } \\
\text { các biến trở và công tắc }\end{array}$ \\
\hline$\% \mathrm{FWHM}\left({ }^{137} \mathrm{Cs}\right)$ & $15,4 \%$ & $13,9 \%$ \\
\hline
\end{tabular}

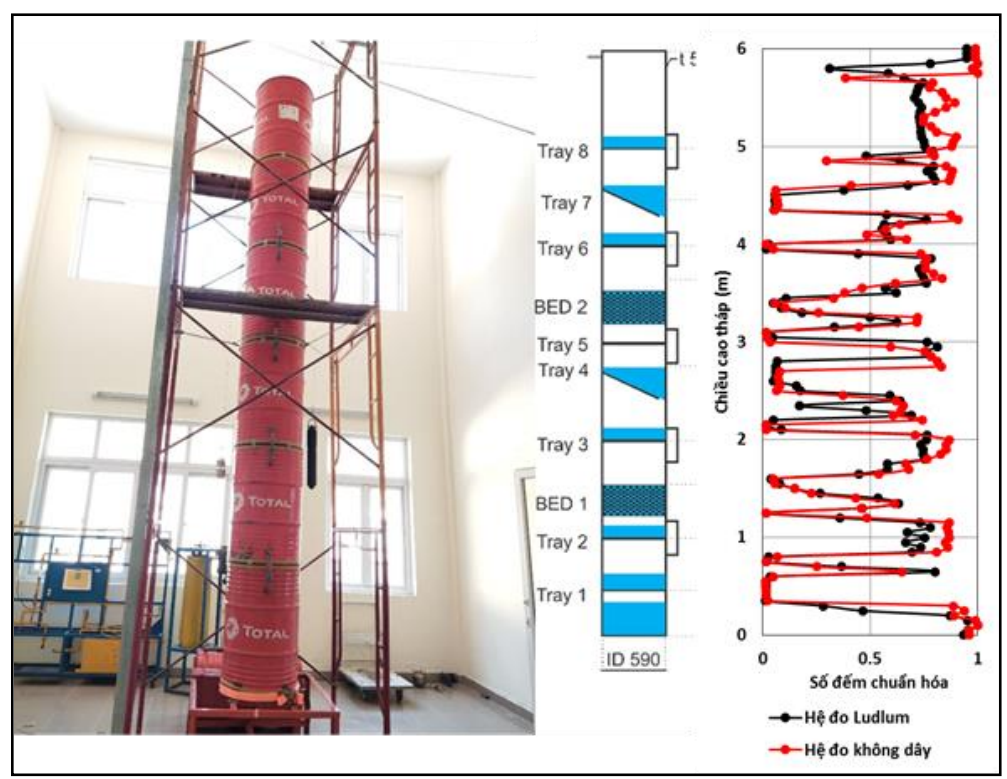

Hình 12. Mô hình tháp chung cất trong công nghiệp và kết quả kiểm tra bằng kỹ thuật soi gamma (đồ thị màu đen là kết quả sủ dụng hệ đo của hãng Ludlum, đồ thị màu đỏ là kết quả sủ dụng hệ đo gamma đơn không dây) 
Đồ thị số đếm của hệ đo gamma đơn kênh không dây thể hiện sự thăng giáng đúng với sự thay đổi vật liệu bên trong tháp. Kết quả đo từ hệ gamma đơn kênh không dây cho thấy tương đồng với kết quả thu được sử dụng hệ đo của hãng Ludlum.

\section{Kết luận}

Hệ đo gamma đơn kênh ứng dụng kỹ thuật truyền phát không dây ứng dụng cho công nghiệp đã cơ bản hoàn thiện. Hệ đo được khảo sát độ phân giải năng lượng và độ ổn định sử dụng nguồn ${ }^{60} \mathrm{Co}$ và ${ }^{137} \mathrm{Cs}$ với khoảng cách truyền phát $230 \mathrm{~m}$. Kết quả cho thấy bề rộng ở một nửa giá trị cực đại ứng với các đỉnh năng lượng lần lượt là $\mathrm{FWHM}^{1173 \mathrm{KeV}}=9,4 \%$ và $\mathrm{FWHM}^{1332 \mathrm{KeV}}=7.6 \%$ đối với phổ gamma ${ }^{60} \mathrm{Co}$ và $\mathrm{FWHM}^{663 \mathrm{KeV}}=15,4 \%$ đối với phổ gamma $\mathrm{Cs}^{137}$ với thời gian ổn định làm việc khoảng 10 giờ. Kết quả đạt được góp phần xác nhận khả năng ứng dụng của hệ đo trong điều kiện hiện trường, góp phần tăng tính hiệu quả của kỹ thuật soi tháp nói riêng và khả năng ứng dụng của kỹ thuật hạt nhân trong công nghiệp nói chung.

Lò̀i cảm ơn: Nghiên cứu này được thục hiện tại Trung tâm Úng dụng kỹ thuật hạt nhân trong công nghiệp (Viện Năng luợng nguyên tử Việt Nam, tại thành phố Đà Lạt, tỉnh Lâm Đồng) với kinh phi do Viện Năng luợng nguyên tử Việt Nam cấp thông qua đề tài mã số CS/19/06-02. Các tác giả xin trân trọng cảm ơn.

\section{TÀI LIẸU THAM KHẢO}

[1] Gerward, L., Rassat, A. (2000). Paul Villard's discovery of gamma rays - A centenary. C. R. Acad. Sci. Paris, 4, 965-973.

[2] Trinh, T. N. H., Hoang, D. T. (2019). Nghiên cứu so sánh kỹ thuật gamma truyền qua và gamma tán xạ trong xác định mật độ của chất lỏng sử dụng phương pháp Monte Carlo. Tạp chí Khoa học Trường Đại học Sư phạm TP Hồ Chí Minh, 16(9), 477-485.

[3] Trần, P. D., Châu, V. T., Nguyễn, H. D. (2005). Phương pháp ghi bức xạ ion hóa. NXB Đại học Quốc gia TP Hồ Chí Minh.

[4] Milam, J. K. (1973). Single-channel analyzers, Instumentation in applied nuclear chemistry (pp. 245-261). New York - London, Plenum Press. 